\title{
CHANGING TRENDS IN CARDIAC DISEASE AND CARDIAC SURGERY*
}

\author{
Dwght C. McGoon
}

FOR A RESTROSPECTIVE VIEW of cardiac surgery to be compressible into a brief report it is necessary to be severely selective of the topics discussed. The subject of cardiac surgery is vast, and its progress has been phenomenal. In the words of one who is a great leader in this century in surgery, himself a general surgeon: "The most important contribution of surgery to the advance of medicine in this century has been intracardiac surgery." Let us touch a few of the high points.

\section{Congenital Cardiac Defects}

In my opinion, possibly biased, cardiac surgery has its strongest roots in the surgery of congenital heart disease. The heart is a remarkable organ, designed after hundreds of millions of years of development to do one single task namely, to propel blood through the circulatory system. The embryological development of the heart seems miraculous, and the wonder is that only about six out of every 1,000 live births result in a congenital deformity of the heart. But for those six, the effect is terribly tragic. One by one the various congenital cardiac defects have yielded to the surgeon's endeavours.

Perhaps we could divide the evolution of surgical treatment of congenital heart disease into four stages. First, by working outside the heart, it became possible to palliate the effects of intracardiac pathology, as introduced in 1944 in the Blalock-Taussig operation. Though ingenious methods were devised to work for brief periods inside the heart, it was not until the successful application of a heart lung machine by Gibbon in 1953 that the era of open heart operations began - the second evolutionary stage. From then until now, one by one the various types of congenital heart anomalies were addressed by surgeons, and a surgical approach was devised. Yet if there were time to analyze the current 1981 management of each defect, we

Dwight C. McGoon, M.D., Thoracic and Cardiovascular Surgery, Mayo Clinic, 200 First St. S.W., Rochester, Minn. 55901, U.S. A.

*Presented in a Panel Discussion of Cardiac Anaesthesia and Surgery at the Annual Meeting, Canadian Anaesthetists' Society, Halifax, N.S., June 1981.

Can. Anaesth. Soc. J., vol. 29, no. 4, July 1982 would find in most instances an unsettled state of affairs. This uncertainty would range all the way from the nature of the extracorporeal circuit and the timing of operation, to contention as to which type of repair is best. Even the name given to many anomalies remains a point of argument.

As an example of this unsettled status, one could select an entity such as transposition of the great arteries, which is an anomaly always accompanied by some associated defect. For the so-called simple form in which an atrial septal defect allows mixing of pulmonic and systemic circulations, the evolutionary cycle has spun full way around, from the early Senning operation and past the various modifications of the Mustard operation, ${ }^{2}$ back to a present resurgence of enthusiasm for that same Senning procedure. But a background of anxiety exists regarding the late result of any type of intra-atrial venous switch operation because of the many potential complications, including arrhythmias, venous pathway obstructions, right ventricular myocardial failure, and tricuspid insufficiency. Therefore hope is expressed for the arterial switch procedures, but much uncertainty remains concerning the appropriateness of a more dangerous operation in the belief that the survivors will enjoy a better long-term result. . $^{3,4}$

The third major stage in our evolutionary progression was the introduction of the extracardiac conduit, first employed by Kirklin in $1964 .^{5}$ In his first case, which had pulmonary atresia, and with pulmonary flow provided by a fistula between the left coronary artery and the pulmonary trunk, a non-valved conduit of pericardium was used. The next year Ross used a valved conduit of homograft aorta, ${ }^{6}$ also for pulmonary atresia; and now the most popular conduit is the synthetic graft containing a bio-prosthetic valve.

In one large series of operations employing the extra-cardiac conduit, ${ }^{7}$ the three most common conditions requiring this technique were pulmonary atresia with ventricular septal defect (24 per cent), truncus arteriosus (26 per cent), and transposition ( 26 per cent), followed by double outlet right ventricle ( 6 per cent) and a miscellany of other conditions. The hospital mortality rates for these complex conditions 330 
tends to be moderately high, ranging from 4 per cent for the rare tetralogy patient requiring a conduit to nearly 50 per cent for the univentricular heart, and an overall average of 25 per cent. By using a large conduit and the largest possible anastomoses, the average trans-conduit gradient at the completion of operation was found to be $23 \mathrm{mmHg}$. This gradient stayed the same or diminished in two-thirds of patients catheterized an average of three years later, but did increase in one-third of patients. The late survival of patients receiving an extracardiac conduit declines at the rate of 3.5 per cent per year, which includes the higher complication rate associated with the earlier use of homograft aortic conduits.

The apparent fourth evolutionary stage of congenital heart surgery is represented by the technique of exclusion of the pulmonary ventricle, first performed by Fontan and Baudet in $1972 .{ }^{8}$ Its ultimate status as a major evolutionary stage depends on the still unknown late result of this operation. The Fontan operation involves establishment of direct atriopulmonary continuity or, in tricuspid atresia, the connection can be made through the rudimentary right ventricle. In the earlier Mayo experience, 29 such operations for pulmonary atresia provided 25 survivors, and 19 of the 20 operations since 1975 were successful. ${ }^{9}$ All survivors but two have a satisfactory result. Also, this method has largely replaced the more complex operations previously attempted for difficult anomalies such as univentricular heart, when pulmonary stenosis is present. For the Fontan operation, a variety of atriopulmonary connections could be used, but we have increasingly preferred direct anastomosis of right atrium to pulmonary artery without insertion of any valves. Using this approach, the result of operations thus far seems much improved over that of the septation operation for univentricular heart.

As a result of the progress of these past 35 years, surgical management is appropriate for nearly all forms of congenital heart disease. Three categories of the more common exceptions seem to exist. When there is an absence of irreplaceable structures, surgeons are thwarted. One example is the hypoplastic left heart syndrome and another is atresia of the entire pulmonary arterial tree. When severe pulmonary vascular obstructive disease exists with advanced degrees of irreversible pulmonary arteriolar changes, so that pulmonary resistance has climbed above 10 units $\cdot \mathrm{M}^{2}$, repair of the intracardiac anomaly is counter-productive. Further- more, some hearts may be involved in a nearly hopeless combination of several complex malformations, any one of which could, if it were an isolated lesion, be repaired but in their combination involve a prohibitive operative risk.

All of the many advances in the technique of operation, of whole body perfusion, and of the use of hypothermia and myocardial protection, have greatly increased the safety of open heart operations, even for the infant. Despite this, and indeed because of these advcances, an issue of great importance today is the determination of the best timing for operation when the infant presents with congenital heart disease. First, it is well to distinguish whether the infant is in distress which is sufficiently severe, even after standard medical treatment, to warrant surgical intervention (Table I). If so, and if the only operative procedures available are direct attack upon the basic pathology, the decision to proceed with direct repair is straightforward. Examples would include congenital aortic stenosis or patent ductus, or the rare instance of cardiac failure in infancy due to atrial septal defect or partial atrioventricular canal.

For most conditions a choice exists between whether it is better to peform a palliative operation on the infant with a view to complete repair later, or to proceed with direct repair primarily. Some conditions result in greatly increased pulmonary blood flow, which causes congestive heart failure, and for these conditions a choice is required between palliation by banding the pulmonary trunk or closure of the septation defect. Most groups have had better results with closure of the ventricular septal defect than with staged operations, which is increasingly true also for complete A-V canal. Where repair is excessively hazardous, as for univentricular heart or corrected transposition, banding is clearly indicated.

In other situations disability results chiefly from inadequate pulmonary blood flow, resulting in severe hypoxaemia. For these patients palliation may be considered, usually by creation of one of the various systemic-to-pulmonary arterial shunts. The argument waxes especially for tetralogy, where direct repair has gained widespread acclaim, especially if the infant has survived his first six months. Under six months of age the pendulum seems to have swung back toward preference for a shunt procedure, with later repair. Again, for more complex lesions such as univentricular heart, palliation during infancy seems the only rational choice. 
TABLE 1

TIMING OF OPERATION FOR INFANT

I. Cardiac disability severe - operation needed early

A. No palliative operation available - therefore, corrective operation

B. Palliative or corrective operation available.

1. Excessive pulmonary flow $\begin{aligned} & \text { band pulmonary artery } \\ & \text { repair defect }\end{aligned}$

2. Inadequate effective pulmonary flow ${ }_{\text {repair defect }}^{\text {shunt }}$

II. Cardiac disability not significant

A. Poor natural history - urgent repair

B. Severe pulmonary hypertension - repair before two years

C. Neither A or B - defer to optimum age

When cardiac disability is not so severe during infancy as to require surgical intervention, a choice is required between direct repair during infancy or at a later age. Repair on an urgent basis is required for conditions known to carry a grave early prognosis even in the absence of profound failure, such as in total anomalous pulmonary venous connection. For those conditions associated with severe pulmonary hypertension repair before two years of age is indicated, since this provides the only good assurance against the progressive development of irreversible obstructive pulmonary vascular disease. Some conditions cause little early or progressive disability, and repair can be deferred either until required by disability or severity of the lesion, as for subvalvular aortic stenosis, or until maximum safety for elective repair can be assured perhaps at about four years of age, as for atrial septal defect.

\section{Valvular Heart Disease}

After certain precocious and premature attempts at mitral commissurotomy, this procedure became a permanent part of the surgical armamentarium beginning in 1948, although in recent years the open rather than closed approach has gradually gained favor. For other forms of acquired valvular disease, succe'ssful operative approaches awaited the achievement of an ongoing involvement in open heart operations. Initially, plastic procedures were attempted, such as debridement of calcified aortic valves and annuloplasty of dilated mitral valves; further experience has led to the abandonment of recon- structive procedures as opposed to replacement for acquired disease of the aortic valve, but to an enhancement of interest in the attempt to reconstruct the natural mitral and tricuspid valves because of the inherent limitations of all replacement valves thus far available.

In addition to the surgical decision whether to repair or replace the diseased atrioventricular valve, current interest focuses on the proper timing of surgical intervention, and the proper choice of a replacement valvular prosthesis when one is needed. In outline, the current practice with respect to the timing of operative intervention is to advise operation for acquired aortic stenosis when resulting cardiac symptoms develop, such as angina, dyspnea, syncope, or congestive heart failure. For aortic insufficiency, even asymptomatic patients should usually have valvular replacement if left ventricular dilatation is significant and progressive. Operative intervention for acquired mitral disease is generally recommended for the patient when clearly deteriorating into NYHA Class III disability.

Huge volumes of print have been devoted to the choice of valve replacement. Many correlations have been conducted between the result of valve replacement and the type of valve used, the preoperative status of the patient and his intraand postoperative management. Extensive engineering studies have been made of the hydrodynamic properties and principles of prosthetic valves. Despite all this attention over a span of decades, the question of which valve is best has not yet been substantially settled for either adults or children. Literally hundreds of differing 


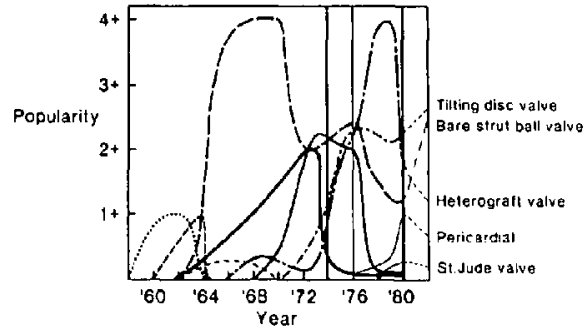

FIGURE 1 The history of popularity of prosthetic valves with reference to the aortic valve. The author's estimate of the popularity of the valve is plotted for any given time with an attempt at prediction beyond 1980. Reading from left to right, the first plot (finely dashed line) was the short-lived technique of debridement of the calcified valve (thus really not a technique of valve replacement). The next dashed line represents the teflon cloth valve, either single cusps or a tri-leaflet type. The next widely dashed line which reached the highest level on the graph is the bare strut ball valve prosthesis, the archetype of which is the Starr-Edwards 1260 valve; note its decline in popularity after 1970 due to competition from several new approaches but its possible resurgence of popularity beyond 1980 . The next wide solid line represents the homograft valve which declined in popularity steeply in the early 1970's. the short low-lying slant-dashed line represents the non-tilting disc type valve. The next line (widely spaced interruption with a dot, beginning in 1965) represents the heterograft porcine valve, first of limited popularity because of the limitation of formaldehyde fixation, but then by late 1970's gaining exceptional popularity in its glutaraldehyde-preserved variation; it is shown to be currently declining steeply in popularity due to the increasing concern about limited durability. The solid line that starts up about 1968 is the cloth-covered ball valve design which has recently largely disappeared from use. The dash-dot line starting in 1970 represents the tilting disc valve, the archetype being the BjorkShiley valve, which has enjoyed rather steady increase in popularity. The fine solid line which first appears about 1976 is the bovine pericardial bioprosthesis of Ionescu-Shiley which has gained in popularity due to its haemodynamic advantage, but which may also suffer from the problem of premature degeneration. Finally, the bi-leaflet all-synthetic valve (St. Jude) has recently made its appearance.

types, models, and concepts of valves have been promoted, tried in patients, and often heralded as the best, only to be discovered in practice to have certain flaws and limitations. This, of course, is the pattern of progress in most fields of human endeavor.

In an effort to survey briefly a highly subjective estimation by one individual of these swings in popular usage of the various valve substitutes through time, Figure I was constructed. The three types of valves which have achieved the greatest popularity have been, successively, the bare strut ball valve, the tilting disc valve, and the porcine bioprosthesis. Each has ultimately fallen short of a sustained position of established superiority, however, because of inherent limitations.

It is well to look at some of the characteristics of cardiac valves which determine their adequacy and limitations. The natural valve, of course, ranks nearly perfect by all criteria, whereas each substitute valve currently available falls short to varying degrees with respect to the principal relevant criteria. These include durability, nonthromogenicity, and hydrodynamic adequacy. The real dilemma with respect to prosthetic valves is that the synthetic are more durable and also more thrombogenic and vice versa for the bioprosthetic. Thus, durability and thrombogenicity seem to be the prime qualities of prosthetic valves which influence the long-term result of valve replacement, overshadowing the differences between them in their hydrodynamic properties. ${ }^{10}$ It is, therefore, of interest and somewhat surprising to find that the advantage claimed for each new type of prosthesis introduced into use has so commonly been its hydrodynamic efficiency (Table II). Similarly, reflection as to the reasons for the decline in usage of a given valve (Table II) suggests that failure in durability and/or thrombogenicity are of importance, whereas hydrodynamic deficiency is not paramount.

\section{Coronary Artery Disease}

The most important killing disease of our age is coronary artery disease, so that surgeons have for several decades yearned for an effective method for ameliorating or overcoming this threat to so large a segment of the population. After limited application of several approaches which had more or less theoretical appeal but little practical effect, the technique of aortocoronary bypass grafting has been applied during the past 13 years to ever-burgeoning numbers of patients. A vast outpouring of data relative to the indications and results for aortocoronary bypass grafting defies ready analysis in this brief review. In summary it can be stated that the appropriate popularity of the operation stems from the low associated risk, its effectiveness in relieving angina pectoris, and its probable favourable influence on salvage of life and of myocardium in at least several subsets of patients. Concern is now justified that the pendulum will swing too far in favour of operation, so 
TABLE II

The "Rise and Fall" of Replacement Valves

\begin{tabular}{|c|c|c|}
\hline \multirow[b]{2}{*}{ Type of valve } & \multicolumn{2}{|c|}{ Reason for } \\
\hline & Introduction & Decline in use \\
\hline Cloth cusp & Hydrodynamic* & Failure in durability \\
\hline Central disc & Hydrodynamic* & Failure in durability \\
\hline Bare strut ball & Hydrodynamic* & (Thrombogenicity) \\
\hline Homograft & Less thrombogenic & $\begin{array}{l}\text { Failure in durability } \\
\text { Limited availability }\end{array}$ \\
\hline Tilting disc & Hydrodynamic & $\begin{array}{c}\text { (Failure in "durability" } \dagger \text { ) } \\
\text { (Thrombogenicity) }\end{array}$ \\
\hline Heterograft & Less thrombogenic & (Failure in durability) \\
\hline Cloth covered ball valve & Less thrombogenic & $\begin{array}{l}\text { Failure in durability } \\
\text { not less thrombogenic }\end{array}$ \\
\hline $\begin{array}{l}\text { Pericardial } \\
\text { Bi-leaflet }\end{array}$ & $\begin{array}{l}\text { Hydrodynamic } \\
\text { Hydrodynamic }\end{array}$ & (?Failure in durability) \\
\hline
\end{tabular}

*Compared with previously unreplaceable diseased valve.

() Valves which remain popular but which would be even more successful were it not for the limitation given.

f"Durability" in this usage refers to thrombotic immobilization of the disc.

that early intervention in minimally symptomatic patients with mild disease will give a net harmful effect to such a patient.

\section{TRENDS in CARDIaC SURGERY}

The frequency of the need for cardiac operation among a given population unit and trends which may be occurring in this frequency are of considerable interest. The population living in Olmsted County, Minnesota, provides unique opportunity for study in this regard, since essentially all residents receive their care locally and their medical records are entirely accessible. A recent study of this population provided such data. ${ }^{\prime \prime}$

The rates of cardiac operations per 10,000 population increased from 4.1 in 1973 to 5.9 in 1977. Operations other than for coronary artery bypass showed no significant trends over time, and the average rate was 2.5 per year. The incidence of coronary artery bypass operations per 10,000 population increased from 1.5 in 1973 to 4.0 in 1977. On the basis of the rates for open heart operations and under conditions similar to those in Olmsted County, a population of approximately 380,000 persons less than 15 years of age would be required to ensure 75 cases requiring open heart operations per year and a population of approximately 230,000 persons more than 14 years of age would provide 200 adult open heart cases per year. Thus, total populations of approximately $1,380,000$ and
310,000 of all ages would be required to meet these minimum case load requirements for surgical teams performing paediatric and adult open heart operations.

\section{SUMMARY}

The trends in cardiac surgery during the four decade or so life history of this specialty have been inexorably toward progress - a greater capacity to relieve suffering and to prolong life for patients afflicted with cardiac disease. It has been a team effort, led by a professional coalition of cardiologist, cardiac anaesthetist, cardiac pathologist and cardiac surgeon, but also with major involvement of nursing, technical and supporting specialties. As technology and capability have progressed and will continue to do so, the challenge for the future, both professionally and socio-economically, will increasingly be our capacity to deliver this demanding, sophisticated and expensive care to expanding proportions of aging individuals, creating a problem which can ultimately be met only by new knowledge and new disciplines of prevention.

\section{REFERENCES}

1. Wangensteen, Owen. In and Out of the Academic Arena. S.G. \& O. 149: 408-416 (1979).

2. Mustard, W.T. Successful Two-Stage Correction of Transposition of the Great Vessels. Surgery 55: 469 (1969). 
3. Fleming, W.H. Why Switch? J. Thorac. Cardiovasc. Surg. 78: 1-2 (1979).

4. Yacoub, M.H. The Case for Anatomic Correction of Transposition of the Great Arteries. J. Thorac. Cardiovasc. Surg. 78: 3-6 (1979).

5. Rastelli, G.C., Ongley, P.A., Davis, G.D. \& KIRKLIN, J.W. Surgical Repair for Pulmonary Valve Atresia with Coronary-Pulmonary Artery Fistula. Report of a Case. Mayo Clin. Proc. 40 521-527 (1965).

6. Ross, D.N. \& Somerville, J. Correction of Pulmonary Atresia with a Homograft Aortic Valve. Lancet 2: 1446-1447 (1966).

7. Ciaravella, J.M., JR., McGoon, D.C. Danielson, G.K., Wallace, R.B., MaIR, D.D. \& ILSTRUP, D.M. Experience with the Intra-Cardiac Conduit. J. Thorac. Cardiovasc. Surg. 78: 920-930 (1979).
8. Fontan, F., Baudet, E. Surgical Repair of Tricuspid Atresia. Thorac. 26: 240 (1971).

9. GAle, A.W., Danielson, G.K., McGoon D.C. WALlaCE, R.B. \& MAIR, D.D. Fontan Procedure for Tricuspid Atresia. Circulation 62(1) 91-96 (1980).

10. Gabbay, S., McQueEn, D.M. Yellin, E.L., BECKER, R.M. \& Frater, R. W.M. In Vitro Hydrodynamic Comparison of Mitral Valve Prostheses at High Flow Rates. J. Thorac. Cardiovasc. Surg. 76: 771-789 (1978).

11. KenNedy, R.H., KenNedy, M.A., McGoon, D.C., PLuth, J.R. \& Nobrega, F.T. Trends in Cardiac Surgery Five-Year Study of a Defined Population. J. Thorac. Cardiovasc. Surg. 80(No. 5): 702-707 (1980). 